\title{
Relevance of Orbital Interactions and Pauli Repulsion in the Metal- Metal Bond of Coinage Metals
}

\author{
Maria B. Brands, ${ }^{\dagger}$ Jörn Nitsch, ${ }^{*}{ }^{\dagger}$ (i) and Célia Fonseca Guerra*, ${ }^{*}+\infty$ \\ ${ }^{\dagger}$ Department of Theoretical Chemistry and Amsterdam Center for Multiscale Modeling, Vrije Universiteit Amsterdam, De Boelelaan \\ 1083, $1081 \mathrm{HV}$ Amsterdam, The Netherlands \\ ${ }^{\ddagger}$ Leiden Institute of Chemistry, Gorlaeus Laboratories, Leiden University, P.O. Box 9502, 2300 RA Leiden, The Netherlands
}

Supporting Information

\begin{abstract}
The importance of relativity and dispersion in metallophilicity has been discussed in numerous studies. The existence of hybridization in the bonding between closed shell $\mathrm{d}^{10}-\mathrm{d}^{10}$ metal atoms has also been speculated, but the presence of attractive $\mathrm{MO}$ interaction in the metal-metal bond is still a matter of an ongoing debate. In this comparative study, a quantitative molecular orbital analysis and energy decomposition is carried out on the metallophilic interaction in atomic dimers $\left(\mathrm{M}^{+} \cdots \mathrm{M}^{+}\right)$and molecular perpendicular $\left[\mathrm{H}_{3} \mathrm{P}-\mathrm{M}-\mathrm{X}\right]_{2}$ (where $\mathrm{M}=$ $\mathrm{Cu}, \mathrm{Ag}$, and $\mathrm{Au} ; \mathrm{X}=\mathrm{F}, \mathrm{Cl}, \mathrm{Br}$, and $\mathrm{I}$ ). Our computational studies prove that besides the commonly accepted dispersive interactions, orbital interactions and Pauli repulsion also play a crucial role in the strength and length of the metal-metal bond. Although for $\mathrm{M}^{+} \ldots \mathrm{M}^{+}$the orbital interaction is larger than the Pauli repulsion, leading to a net attractive $\mathrm{MO}$ interaction, the bonding mechanism in perpendicular $\left[\mathrm{H}_{3} \mathrm{P}-\mathrm{M}-\mathrm{X}\right]$ dimers is different due to the larger separation between the donor and acceptor orbitals. Thus, Pauli repulsion is much larger, and two-orbital, four-electron repulsion is dominant.
\end{abstract}

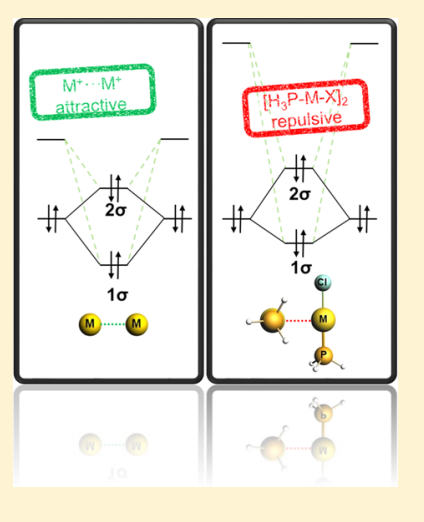

\section{INTRODUCTION}

Closed-shell $\mathrm{d}^{10}-\mathrm{d}^{10}$ interactions are an interesting research target both from an experimental as well as from a theoretical perspective. ${ }^{1}$ From a practical point of view, these interactions can be used for the design of supramolecular (di-, oligo-, or polymeric) structures. ${ }^{1 j}$ Furthermore, these structures show very interesting luminescence properties, including mechanochromic or vaporchromic behavior ${ }^{2 a-1}$ and are discussed as important viable intermediate in gold-catalyzed hydroarylation reactions. ${ }^{2 \mathrm{~m}}$ In addition, complexes displaying metallophilic interactions are also considered as potential antitumor agents. ${ }^{3}$ The strength of aurophilic interactions has been determined experimentally in some cases and is comparable to moderate $\mathrm{H}$ bonds $(7-12 \mathrm{kcal} / \mathrm{mol}) .{ }^{4}$ However, for an effective tuning of such interactions, it is crucial to understand the bonding mechanism behind $\mathrm{d}^{10}-\mathrm{d}^{10}$ metallophilic interactions. This mechanism is still a subject of a long-standing debate and has proven quite a challenge for quantum chemistry. There is a broad consensus that relativity and dispersion in metallophilicity play an important role. ${ }^{1}$ From a molecular orbital (MO) perspective, attractive interaction is not expected a priori in closed-shell atoms (consider $\mathrm{He}_{2}$ or a hydride dimer as examples, where two-orbital, four-electron repulsion are dominant). However, pioneering work conducted by Hoffmann et al. in 1978, concluded from extended Hückel theory (EHT) that hybridization of empty $(n+1)$ s and filled $n \mathrm{~d}_{z}^{2}$ orbitals is present and accounts for a covalent metal-metal bond in systems such as dicationic $\mathrm{Cu}^{+} \ldots \mathrm{Cu}^{+}$or in neutral $\left[\mathrm{Au}_{2}\left(\mathrm{~S}_{2} \mathrm{PH}_{2}\right)_{2}\right]^{5}$. Since then different views have been presented. While others including Schmidbaur ${ }^{6}$ and Mingos ${ }^{7}$ also mentioned the importance of $5 \mathrm{~d}$ and $6 \mathrm{~s}$ hybridization in the bonding of Au clusters, Pyykkö concluded that there is no hybridization present. $^{8} \mathrm{He}$ showed that electron correlation strengthened by relativity is of great importance (i.e., that dispersive effects are only responsible for the attractive interaction in coinage metal dimers). In turn, Schwarz ${ }^{9}$ could find for the perpendicular $\left[\mathrm{H}_{3} \mathrm{P}-\mathrm{Au}-\mathrm{Cl}\right]_{2}$ (Figure 1; structure
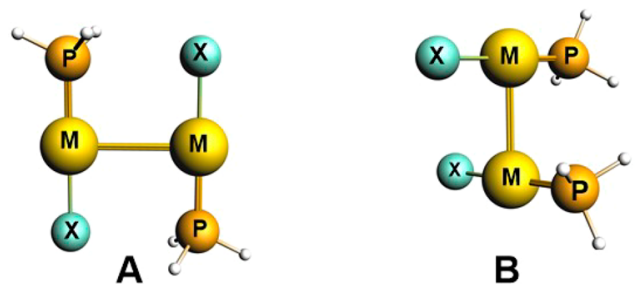

Figure 1. Head-to-tail $(\mathbf{A})$ and perpendicular $(\mathbf{B})\left[\mathrm{H}_{3} \mathrm{P}-\mathrm{M}-\mathrm{X}\right]_{2}$ with $\mathrm{M}=\mathrm{Cu}, \mathrm{Ag}$, and $\mathrm{Au} ; \mathrm{X}=\mathrm{F}, \mathrm{Cl}, \mathrm{Br}$, and $\mathrm{I}(\mathrm{X}-\mathrm{M}-\mathrm{M}-\mathrm{X}$ and $\mathrm{P}-\mathrm{M}-$ $\mathrm{M}-\mathrm{P}$ dihedral angles are constrained to $180.0^{\circ}(\mathrm{A})$ and $90.0^{\circ}$ (B). For full details, see the Supporting Information.

B, $\mathrm{M}=\mathrm{Au}, \mathrm{X}=\mathrm{Cl}$ ) an orbital interaction energy of $-21 \mathrm{kcal} /$ mol, which he also attributed to orbital mixing. However, the conclusions presented by Schwarz are derived from a simple local $\mathrm{X} \alpha$ exchange potential (S-LDF) DFT calculation and could be attributed to the fortuitous cancellation of errors.

Received: November 29, 2017

Published: February 12, 2018 
At this point, no consensus is reached on the bonding mechanism in metallophilic interactions. Thus, we have analyzed the bonding mechanism in the framework of Kohn-Sham molecular orbital theory and would like to emphasize a neglected aspect of this discussion: the importance of Pauli repulsion and orbital interaction in metallophilicity.

\section{THEORETICAL METHODS}

Herein, we present an energy decomposition analysis (EDA) ${ }^{10}$ of the metal-metal bond in perpendicular dimers such as $\left[\mathrm{H}_{3} \mathrm{P}-\mathrm{M}-\mathrm{X}\right]_{2}$ (see Figure $1,(\mathbf{B}), \mathrm{M}=\mathrm{Cu}, \mathrm{Ag}$, and $\mathrm{Au} ; \mathrm{X}=\mathrm{F}, \mathrm{Cl}, \mathrm{Br}$, and $\mathrm{I}$ ) and compared these systems with simple metal dimers $\left(\mathrm{M}^{+} \ldots \mathrm{M}^{+}\right)$. De Proft used a similar approach for analyzing the interaction in $[\mathrm{NHC}-\mathrm{M}-\mathrm{Cl}]_{2}$ (where NHC is an $\mathrm{N}$-heterocyclic carbene). ${ }^{11}$ In contrast to our studies, a head-to-tail arrangement (see Figure 1; structure type A) of these dimers was used instead, which includes additional ligand-ligand interactions besides metallophilicity (vide infra).

We performed a benchmark of our dispersion-corrected DFT methods (see Tables S1-S3) and decided to use the ZORA-BLYPD3(BJ)/TZ2P level of theory (MAE: $0.3-2.4 \mathrm{kcal} / \mathrm{mol}$; Supporting Information). The dimerization energy $\left(\Delta E_{\mathrm{dim}}\right)$ of forming $\left[\mathrm{H}_{3} \mathrm{P}-\mathrm{M}-\right.$ $\mathrm{X}]_{2}$ from their respective monomers can be decomposed in the following terms:

$$
\begin{aligned}
& \Delta E_{\text {dim }}=\Delta E_{\text {int }}+\Delta E_{\text {prep }} \\
& \Delta E_{\text {int }}=\Delta E_{\text {Pauli }}+\Delta V_{\text {elstat }}+\Delta E_{\text {disp }}+\Delta E_{\text {oi }}
\end{aligned}
$$

$\Delta E_{\text {prep }}$ is the preparation or strain energy of the two (deformed) fragments $\left(\left[\mathrm{H}_{3} \mathrm{P}-\mathrm{M}-\mathrm{X}\right]^{\ddagger}\right)$ and $\Delta E_{\text {int }}$ is the interaction energy between these deformed reactants (eq 1). The latter can be further analyzed in the conceptual framework provided by the Kohn-Sham molecular orbital model and decomposed into physically meaningful terms (eq 2). The EDA quantifies the Pauli-repulsive orbital interactions $\left(\Delta E_{\text {Pauli }}\right)$ between same-spin electrons, the electrostatic interaction $\left(\Delta V_{\text {elstat }}\right)$, interaction due to dispersion forces $\left(\Delta E_{\text {disp }}\right)$, and orbital interactions $\left(\Delta E_{\mathrm{oi}}\right)$ that emerge from charge transfer (interaction between occupied orbitals on one fragment with unoccupied orbitals on the other fragment, including donor-acceptor interactions) and polarization (empty-occupied orbital mixing on one fragment due to the presence of the other fragment).

\section{RESULTS AND DISCUSSION}

The equilibrium bond distances $r$ of structures $\mathbf{A}$ (head-to-tail) and $\mathbf{B}$ (perpendicular) for $\mathrm{M}=\mathrm{Cu}, \mathrm{Ag}$, and $\mathrm{Au}$ and $\mathrm{X}=\mathrm{F}, \mathrm{Cl}$, $\mathrm{Br}$, and I can be found in Table S4. For all cases, the head-totail dimers are more stable with respect to dissociation than the structures of the perpendicular arrangement. Thus, structures A have more attractive dimerization energies (A: between -16 and $-24 \mathrm{kcal} / \mathrm{mol}$; B: between -8 and -15$)$. The difference in dimer stability between $\mathbf{A}$ and $\mathbf{B}$ becomes less pronounced the larger the halogen atom $\mathrm{X}$ becomes $(\mathrm{F}<\mathrm{Cl}<\mathrm{Br}<\mathrm{I})$, which is accompanied in structure $\mathbf{A}$ by an increase of the $r_{\mathrm{MM}}$ distance (as an example, $\left.\left[\mathrm{H}_{3} \mathrm{P}-\mathrm{Cu}-\mathrm{F}\right]_{2}: r_{\mathrm{MM}}=2.76 \AA \AA^{\circ} ; \mathrm{H}_{3} \mathrm{P}-\mathrm{Cu}-\mathrm{I}\right]_{2}$ : $\left.r_{\mathrm{MM}}=3.69 \AA\right)$. This increase in the equilibrium metal-metal distance is not found for the perpendicular dimers $\left(\left[\mathrm{H}_{3} \mathrm{P}-\mathrm{Cu}-\right.\right.$ $\left.\mathrm{F}]_{2}: r_{\mathrm{MM}}=2.71 \AA ;\left[\mathrm{H}_{3} \mathrm{P}-\mathrm{Cu}-\mathrm{I}\right]_{2}: r_{\mathrm{MM}}=2.69 \AA\right)$. It is clear that for the head-to-tail arrangement additional ligand-ligand interactions lead to a stabilization of the dimer. Thus, we will focus in the following on structure $\mathbf{B}$, where ligand-ligand interactions are minimized.

In order to examine the metal-metal bond exclusively, we will first consider the MO diagram and energy decomposition of the bare metal dimers $\left(\mathrm{M}^{+} \cdots \mathrm{M}^{+}\right)$, in the absence of any ligand. We choose a metal-metal distance $\left(r_{\mathrm{MM}}\right)$, which is equal to the equilibrium distance in perpendicular $\left[\mathrm{H}_{3} \mathrm{P}-\mathrm{M}-\right.$
Cl] dimers (Cu: $2.71 \AA ̊$; Ag: $2.97 \AA ̊ A$; $3.15 \AA ̊$ ). The MO diagram for the $\mathrm{M}^{+} \ldots \mathrm{M}^{+}$interaction is displayed in Figure 2.

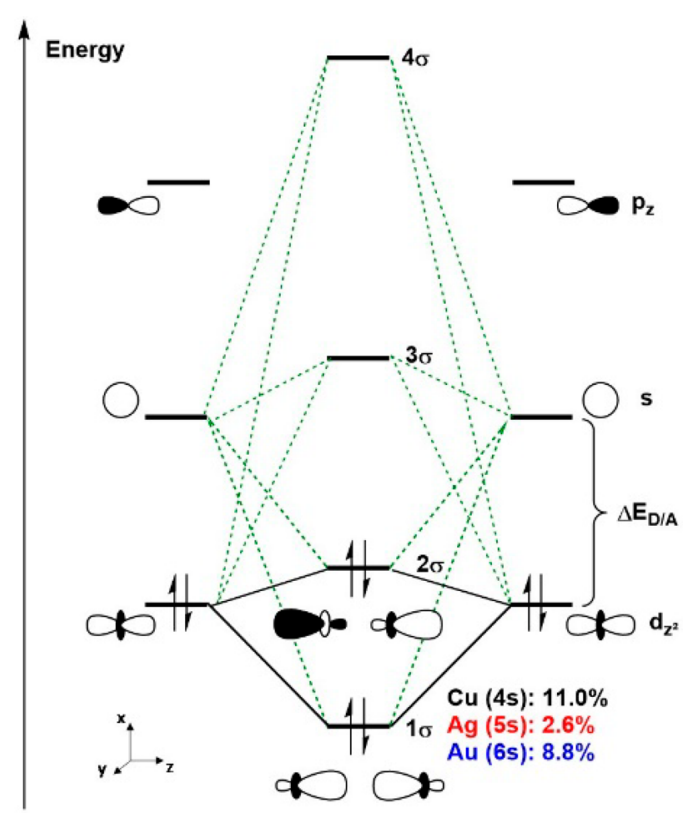

Figure 2. Schematic $\mathrm{MO}$ diagram for $\mathrm{M}^{+} \cdots \mathrm{M}^{+}$. s-Orbital contribution [in \%] to $1 \sigma$ is also shown (compare text). The green dotted lines indicate the mixing in of empty $\mathrm{s}$ and filled $\mathrm{d}_{z}{ }^{2}$ in the bonding and antibonding MOs. Distance $\left(r_{\mathrm{MM}}\right)$ is shown in Table 1.

It is apparent that the $1 \sigma$ orbital is the bonding and $2 \sigma$ is the antibonding combination of the metal-metal interaction. Hence, our results derived from KS-MO theory are in a qualitative agreement with the extended Hückel theory (EHT) picture from Hoffmann. ${ }^{5 a}$

Figure 2 and Table S5 show the percentages of the relevant orbitals derived from a gross orbital population analysis. Mixing in of the empty $(n+1)$ s orbital leads to a stabilization of the $1 \sigma$ and to a smaller extend of the $2 \sigma$. The largest $(n+1)$ s orbital admixture to $1 \sigma$ is found for $\mathrm{Cu}(11.0 \%)$, followed by $\mathrm{Au}$ $(8.8 \%)$ and $\mathrm{Ag}(2.6 \%)$. The admixture of $(n+1) \mathrm{p}_{z}$ is in general much smaller and is up to $3 \%(\mathrm{Cu})$ and smaller for gold $(2 \%)$ and silver (1\%) (see Table S5).

The EDA results are shown in Table 1 and reveal an entirely positive (repulsive) interaction energy $\left(\Delta E_{\text {int }}\right)$, where the least

Table 1. EDA of $\mathrm{M}(1)^{+} \ldots \mathrm{M}(2)^{+a}$

$\begin{array}{ccccccc}\mathrm{M}^{+} \cdots \mathrm{M}^{+} & r_{\mathrm{MM}}[\AA] & \Delta E_{\text {Pauli }} & \Delta V_{\text {elstat }} & \Delta E_{\text {disp }} & \Delta E_{\text {oi }} & \Delta E_{\text {int }} \\ \mathrm{Cu}^{+} \ldots \mathrm{Cu}^{+} & 2.71 & 3.6 & 119.1 & -2.3 & -21.8 & 98.7 \\ \mathrm{Ag}^{+} \cdots \mathrm{Ag}^{+} & 2.97 & 3.8 & 109.2 & -2.5 & -12.3 & 98.2 \\ \mathrm{Au}^{+} \ldots \mathrm{Au}^{+} & 3.15 & 4.0 & 102.6 & -2.5 & -19.2 & 84.9\end{array}$

${ }^{a}$ All values are in $\mathrm{kcal} / \mathrm{mol}$. $r_{\mathrm{MM}}$ is equal to the equilibrium distance in $\left[\mathrm{H}_{3} \mathrm{P}-\mathrm{M}-\mathrm{Cl}\right]_{2}$.

repulsive $\Delta E_{\text {int }}$ is found for $\mathrm{Au}(84.9 \mathrm{kcal} / \mathrm{mol})$ and being almost equal for $\mathrm{Cu}$ and $\mathrm{Ag}$ (98.7 and $98.2 \mathrm{kcal} / \mathrm{mol})$. This repulsive interaction is mainly due to the (expected) large electrostatic repulsion of two cationic metal ions experiencing each other $\left(\Delta V_{\text {elstat }}\right.$ : Au: $102.6 \mathrm{kcal} / \mathrm{mol} ; \mathrm{Ag}: 109.2 \mathrm{kcal} / \mathrm{mol}$; $\mathrm{Cu}: 119.1 \mathrm{kcal} / \mathrm{mol})$. The difference in $\Delta V_{\text {elstat }}$ can be explained by the difference in $r_{\mathrm{MM}}(\mathrm{Cu}: 2.71 \AA$, Ag: $2.97 \AA$ and $\mathrm{Au}: 3.01$ $\AA)$. However, in accordance with the finding of Hoffmann and 

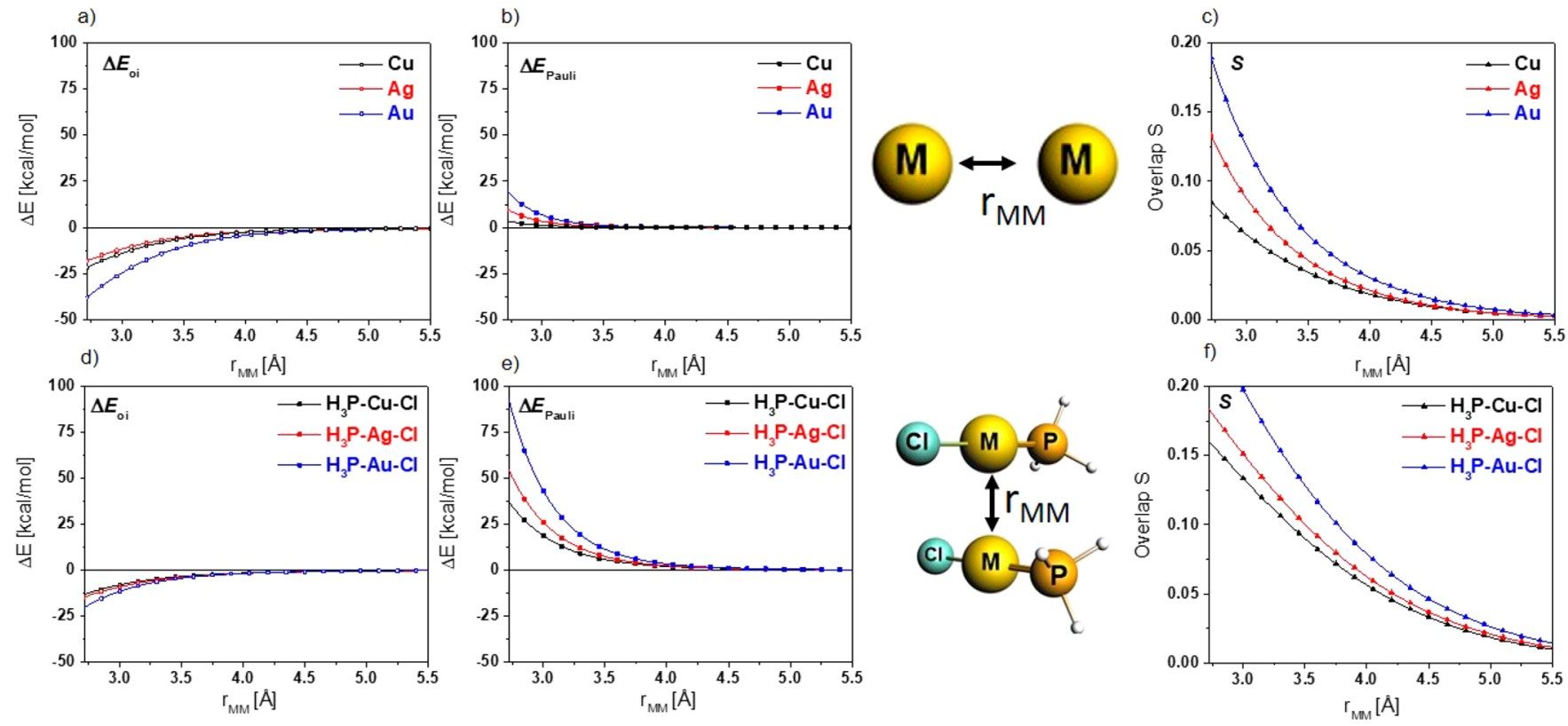

Figure 3. Orbital interaction $\left(\Delta E_{\mathrm{oi}}\right)$, Pauli repulsion $\left(\Delta E_{\mathrm{Pauli}}\right)$, and orbital overlap $S$ of the five highest occupied $\mathrm{FMOs}$ of $\mathrm{M}^{+} \ldots \mathrm{M}^{+}(\mathrm{a}-\mathrm{c})$ and $\left[\mathrm{H}_{3} \mathrm{P}-\right.$ $\mathrm{M}-\mathrm{Cl}]_{2}(\mathrm{~d}-\mathrm{f})$ at different distances: $\mathrm{Cu}$ (black), $\mathrm{Ag}$ (red), and $\mathrm{Au}$ (blue); $\mathrm{X}-\mathrm{M}-\mathrm{M}-\mathrm{X}$ and $\mathrm{L}-\mathrm{M}-\mathrm{M}-\mathrm{L}$ dihedral angle are constrained to $90.0^{\circ}$. For full details, see the Supporting Information.

in contrast to Pyykkö's conclusion, an attractive orbital interaction $\left(\Delta E_{\mathrm{oi}}\right)$ is found $(\mathrm{Cu}:-21.8 \mathrm{kcal} / \mathrm{mol}$; $\mathrm{Ag}:-12.2$ $\mathrm{kcal} / \mathrm{mol}$; Au: $-19.2 \mathrm{kcal} / \mathrm{mol})$.

The trend in $\Delta E_{\mathrm{oi}}$ can traced back to the contribution of metal $(n+1)$ s to the $1 \sigma$, which is related to the energy gap $\left(\Delta E_{\mathrm{D} / \mathrm{A}}\right)$ between the $n \mathrm{~d}_{z^{2}}$ (donor) and $(n+1) \mathrm{s}$ (acceptor) orbital (Cu: $1.62 \mathrm{eV}, \mathrm{Ag}: 4.13 \mathrm{eV}$ and $\mathrm{Au}: 1.97 \mathrm{eV})$. The small energy gap $\left(\Delta E_{\mathrm{D} / \mathrm{A}}\right)$ for $\mathrm{Au}^{+} \ldots \mathrm{Au}^{+}$is a consequence of the strong relativistic effects present for this metal, which causes a destabilization of the metal $5 \mathrm{~d}$ and a stabilization $6 \mathrm{~s}$ orbital. ${ }^{12}$ Pauli repulsion $\left(\Delta E_{\text {Pauli }}\right)$, which is caused by antibonding orbital overlap (i.e., the $2 \sigma \mathrm{MO}$ and other filled d-orbitals) is much smaller $(3.6-4.0 \mathrm{kcal} / \mathrm{mol})$, making the closed shell interaction shown in Figure 2 net attractive. Thus, for the bare metal dimers, the closed shell $\mathrm{d}^{10}-\mathrm{d}^{10}$ two-orbital, four-electron repulsion is weak, due to strong mixing in of the metal s orbital and the relative small antibonding orbital overlap $(\mathrm{Cu}: 8.5 \times$ $10^{-2}$; Ag: $9.1 \times 10^{-2}$; Au: $\left.10.0 \times 10^{-2}\right)$. Obviously, the energy terms of the EDA and the overlap $S$ are functions of the metalmetal distance $\left(r_{\mathrm{MM}}\right)$, thus we have examined the different EDA terms for a range of metal-metal distances (see Figure 3a and $3 \mathrm{~b}$ for $\Delta E_{\mathrm{oi}}$ and $\Delta E_{\text {Pauli }}$ Figure $\mathrm{S} 2$ for the full EDA).

However, the relative importance of each energy term remains unchanged (i.e., a strong electrostatic repulsion, large orbital interaction, and small Pauli repulsion). If the interaction energy is compared at the same metal-metal distance, then the most stabilizing $\Delta E_{\mathrm{oi}}$ curve is found for $\mathrm{Au}$ followed by the almost identical curves for $\mathrm{Cu}$ and $\mathrm{Ag}$ (Figure 3a). In addition to the relative small value for $\Delta E_{\mathrm{D} / \mathrm{A}}$ the orbital overlap $\mathrm{S}$ for $\mathrm{Au}$ is larger than for $\mathrm{Cu}$. Furthermore, Pauli repulsion plays a minor role and is smallest for $\mathrm{Cu}$, followed by $\mathrm{Ag}$ and then by $\mathrm{Au}$ (Figure 3b), due to the smallest orbital overlap for copper $(\mathrm{Cu}<\mathrm{Ag}<\mathrm{Au}$; Figure 3c). Succinctly, apart from the expected large electrostatic repulsion, orbital interaction is an important term in determining the metallophilic interaction of closed shell $\mathrm{M}^{+} \cdots \mathrm{M}^{+}$systems and is mainly caused by mixing in (or hybridization) of $(n+1)$ s acceptor orbitals.
We will now consider the more realistic dicoordinated perpendicular model structures (Figure 1 ; structure B). A simplified $\mathrm{MO}$ for $\left[\mathrm{H}_{3} \mathrm{P}-\mathrm{Au}-\mathrm{Cl}\right]_{2}$ is shown in Figure 4 (see

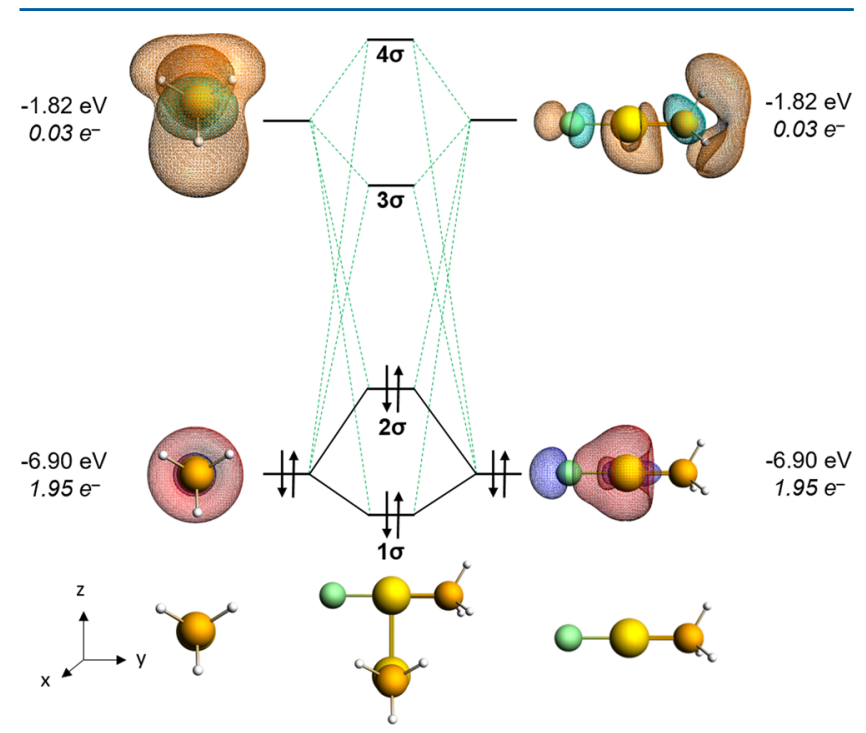

Figure 4. $\mathrm{MO}$ diagram for $\left[\mathrm{H}_{3} \mathrm{P}-\mathrm{Au}-\mathrm{Cl}\right]_{2}$. The black lines indicate the formation of bonding $1 \sigma$ and antibonding combinations $2 \sigma$. The green dotted lines indicate the mixing in of empty and filled FMOs in the bonding and antibonding MOs. The isovalue is $0.03 \mathrm{e}^{-} / a_{0}^{3}$.

the Supporting Information for other structures). It is apparent from these plots that the mixing in of acceptor fragment molecular orbital(s) (FMO) leads to a stabilization of the $1 \sigma$ and the $2 \sigma$. With respect to the metal-metal interaction, $1 \sigma$ is bonding, whereas $2 \sigma$ is antibonding, which is qualitatively equivalent to the situation in Figure 2, but the stabilization of these orbitals is now smaller, and the acceptor orbital is to a large extend a ligand orbital. Thus, this situation will lead, in 
Table 2. Results of the EDA for the Perpendicular $\left[\mathrm{H}_{3} \mathrm{P}-\mathrm{M}-\mathrm{X}\right]$ Dimers ${ }^{a}$

\begin{tabular}{|c|c|c|c|c|c|c|c|c|c|}
\hline $\mathrm{X}$ & M & $r_{\mathrm{MM}}[\AA]$ & $\Delta E_{\text {Pauli }}$ & $\Delta V_{\text {elstat }}$ & $\Delta E_{\text {disp }}$ & $\Delta E_{\mathrm{oi}}$ & $\Delta E_{\text {int }}$ & $\Delta E_{\mathrm{dim}}$ & occupancy of donor orbital ${ }^{b}$ \\
\hline \multirow{3}{*}{$\mathrm{F}$} & $\mathrm{Cu}$ & 2.71 & 31.4 & -22.0 & -8.4 & -11.2 & -10.2 & -9.9 & 1.93 \\
\hline & $\mathrm{Ag}$ & 3.00 & 22.7 & -16.1 & -9.1 & -7.7 & -10.2 & -10.0 & 1.95 \\
\hline & $\mathrm{Au}$ & 3.18 & 24.1 & -16.6 & -8.2 & -7.3 & -8.0 & -7.9 & 1.96 \\
\hline \multirow{3}{*}{$\mathrm{Cl}$} & $\mathrm{Cu}$ & 2.71 & 38.2 & -25.7 & -11.7 & -13.3 & -12.5 & -12.1 & 1.93 \\
\hline & $\mathrm{Ag}$ & 2.97 & 28.4 & -19.4 & -10.8 & -9.6 & -11.4 & -11.1 & 1.95 \\
\hline & $\mathrm{Au}$ & 3.15 & 29.0 & -19.4 & -10.8 & -8.6 & -9.9 & -9.7 & 1.95 \\
\hline \multirow{3}{*}{$\mathrm{Br}$} & $\mathrm{Cu}$ & 2.70 & 43.1 & -28.9 & -13.1 & -14.9 & -13.8 & -13.4 & 1.93 \\
\hline & $\mathrm{Ag}$ & 2.95 & 31.7 & -21.7 & -12.0 & -10.6 & -12.5 & -12.2 & 1.95 \\
\hline & $\mathrm{Au}$ & 3.13 & 32.1 & -21.5 & -12.0 & -9.5 & -10.9 & -10.7 & 1.95 \\
\hline \multirow{3}{*}{ I } & $\mathrm{Cu}$ & 2.69 & 50.0 & -33.4 & -15.2 & -16.9 & -15.6 & -15.1 & 1.93 \\
\hline & $\mathrm{Ag}$ & 2.95 & 36.6 & -25.0 & -13.8 & -12.0 & -14.2 & -13.8 & 1.95 \\
\hline & $\mathrm{Au}$ & 3.11 & 36.8 & -24.7 & -12.3 & -10.6 & -10.8 & -10.6 & 1.96 \\
\hline
\end{tabular}

${ }^{a}$ All values are in $\mathrm{kcal} / \mathrm{mol}$. The equilibrium distances $r_{\mathrm{MM}}$ are also shown. ${ }^{b}$ The initial occupancy of donor orbital $\mathrm{D}(1)$ or $\mathrm{D}(2)$ (see also Figure 5 ).

contrast to Figure 2, to a net repulsive $\mathrm{MO}$ interaction (vide infra).

Table 2 shows the dimerization energies $\left(\Delta E_{\text {dim }}\right)$ and the results of the EDA for various perpendicular $\left[\mathrm{H}_{3} \mathrm{P}-\mathrm{M}-\mathrm{X}\right]$ dimers at their equilibrium distances. In all cases, $\left[\mathrm{H}_{3} \mathrm{P}-\mathrm{Cu}-\right.$ $\mathrm{X}]_{2}$ has the most attractive (i.e., most negative) dimerization energies $(-10$ to $-15 \mathrm{kcal} / \mathrm{mol})$, followed by $\left[\mathrm{H}_{3} \mathrm{P}-\mathrm{Ag}-\mathrm{X}\right]_{2}$ $(-10$ to $-14 \mathrm{kcal} / \mathrm{mol})$ and then by $\left[\mathrm{H}_{3} \mathrm{P}-\mathrm{Au}-\mathrm{X}\right]_{2}(-8$ to $-11 \mathrm{kcal} / \mathrm{mol})$, except for $\mathrm{X}=\mathrm{F}$, where $\Delta E_{\text {dim }}$ is almost equal for $\mathrm{Ag}$ and $\mathrm{Cu}$. The most attractive dimerization energy is found for $\left[\mathrm{H}_{3} \mathrm{P}-\mathrm{Cu}-\mathrm{I}\right]_{2}(-15 \mathrm{kcal} / \mathrm{mol})$, while the least attractive is found for $\left[\mathrm{H}_{3} \mathrm{P}-\mathrm{Au}-\mathrm{F}\right]_{2}(-8 \mathrm{kcal} / \mathrm{mol})$. The dimerization energy $\left(\Delta E_{\text {dim }}\right)$ and interaction energy $\left(\Delta E_{\text {int }}\right)$ do not differ much; the preparation or strain energy $\left(\Delta E_{\text {prep }}\right.$ in eq 1) ranges for all $\left[\mathrm{H}_{3} \mathrm{P}-\mathrm{M}-\mathrm{X}\right]_{2}$ systems between 0.2 and 0.4 $\mathrm{kcal} / \mathrm{mol}$. Thus, the dimerization does not lead to a large geometric change or deformation in the linear $\left[\mathrm{H}_{3} \mathrm{P}-\mathrm{M}-\mathrm{X}\right]$ monomers. The most attractive terms for all dimers are the electrostatic interactions. While $\Delta V_{\text {elstat }}$ for equal halogens $(\mathrm{X})$ are similar for all $\left[\mathrm{H}_{3} \mathrm{P}-\mathrm{Ag}-\mathrm{X}\right]_{2}$ and $\left[\mathrm{H}_{3} \mathrm{P}-\mathrm{Au}-\mathrm{X}\right]_{2}$, ranging from -16 to $-25 \mathrm{kcal} / \mathrm{mol}$ (from $\mathrm{F}$ to $\mathrm{I}$ ), these interactions differ significantly for $\left[\mathrm{H}_{3} \mathrm{P}-\mathrm{Cu}-\mathrm{X}\right]$ dimers by an absolute value of about $6-8 \mathrm{kcal} / \mathrm{mol}$ (i.e., the electrostatic interactions are more attractive for $\mathrm{Cu}$ than for $\mathrm{Ag}$ and $\mathrm{Au}$ ). This is due a larger electronic charge density overlap for $\left[\mathrm{H}_{3} \mathrm{P}-\mathrm{Cu}-\mathrm{X}\right]_{2}$ because of the shorter equilibrium distances for these structures (Figures S3-S6). ${ }^{10 \mathrm{~b}}$ A similar trend (opposite in sign) is found for the Pauli repulsion, where the values for $\mathrm{Cu}$ range between 31 and $50 \mathrm{kcal} / \mathrm{mol}$, whereas for $\mathrm{Ag} / \mathrm{Au}$ they are between 23 and $37 \mathrm{kcal} / \mathrm{mol}$. In contrast to the bare metal dimers, the Pauli repulsion is for all structures the most dominant factor (largest absolute values) of determining the dimerization energy. Similar to the bare metal dimers, we found a non-neglectable orbital interaction energy $\left(\Delta E_{\mathrm{oi}}\right)$. The most attractive orbital interaction is found for $\mathrm{Cu}(-12$ to $-17 \mathrm{kcal} / \mathrm{mol})$, followed by $\mathrm{Ag}(-8$ to $-12 \mathrm{kcal} / \mathrm{mol})$, and then closely followed by $\mathrm{Au}(-7$ to $-11 \mathrm{kcal} / \mathrm{mol})$.

In general, $\Delta E_{\mathrm{oi}}$ in $\left[\mathrm{H}_{3} \mathrm{P}-\mathrm{M}-\mathrm{X}\right]_{2}$ can either be caused by polarization (P) (i.e., mixing in of virtual orbitals on one fragment due to the presence of the other fragment; Figure 5, vertical arrows) or by charge transfer from one fragment to the unoccupied orbitals of the other (donor-acceptor interaction; Figure 5, diagonal arrows). We performed calculations where we deleted the virtual orbitals of one monomer $\left(\mathrm{A}(2)^{*}\right.$, in Figure 5 right). After removing these orbitals, the donor orbital $\mathrm{D}(1)$ can no longer transfer electrons via D-A interactions to

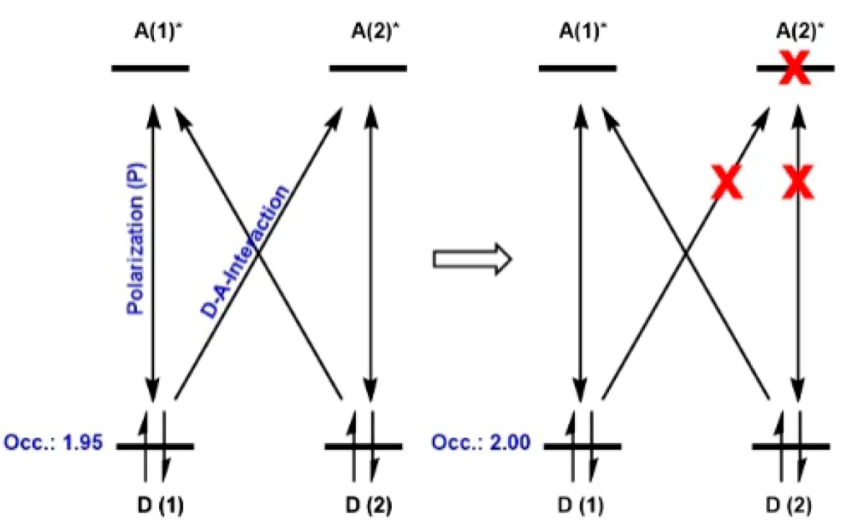

Figure 5. Schematic picture of donor-acceptor (D-A) interactions $\left(\right.$ e.g., $\left.\mathrm{D}(1) \rightarrow \mathrm{A}(2)^{*}\right)$ and polarization (P; e.g., $\left.\mathrm{D}(1) \rightarrow \mathrm{A}(1)^{*}\right)$. Change in occupation in $\left[\mathrm{H}_{3} \mathrm{P}-\mathrm{Au}-\mathrm{Cl}\right]_{2}$ is shown if virtual orbitals $\mathrm{A}(2)^{*}$ of fragment 2 (i.e., of one $\left[\mathrm{H}_{3} \mathrm{P}-\mathrm{Au}-\mathrm{Cl}\right]$ monomer) are removed.

$\mathrm{A}(2) *$. However, the vertical polarization $\mathrm{D}(1) \rightarrow \mathrm{A}(1) *$ can still occur. We carefully examined the gross electron population of the relevant frontier orbitals. As seen in Figure 5, for $\left[\mathrm{H}_{3} \mathrm{P}-\right.$ $\mathrm{Au}-\mathrm{Cl}]_{2}$ the population of $\mathrm{D}(1)$ changes from 1.95 to 2.00 when removing the virtual orbitals $\mathrm{A}(2) *$. We found this behavior for all $\left[\mathrm{H}_{3} \mathrm{P}-\mathrm{M}-\mathrm{X}\right]$ dimers (see last column of Tables 2 and S6); therefore, we conclude that polarization plays only a minor role in these systems. We found, however, that polarization becomes more important for $\mathrm{M}^{+} \cdots \mathrm{M}^{+}$(see Table S7).

In contrast to the bonding mechanism found for bare metals dimers, the Pauli repulsion compensates for the orbital interactions by $13-33 \mathrm{kcal} / \mathrm{mol}$ for $\left[\mathrm{H}_{3} \mathrm{P}-\mathrm{M}-\mathrm{X}\right]_{2}$. This indicates inherently that occupied antibonding orbital combinations compensate the occupied bonding (i.e., two-orbital, four-electrons repulsion is dominant in Figure 4). This finding agrees with Pyykkö's conclusion regarding the overall absence of $\mathrm{MO}$ interactions for $\left[\mathrm{H}_{3} \mathrm{P}-\mathrm{M}-\mathrm{X}\right]_{2}$ and can be derived from a series of EDA at different metal-metal-distances as well (see Figures $3 \mathrm{~d}-\mathrm{f}$ and $\mathrm{S} 2-\mathrm{S} 5$ ). Nevertheless, without the $\Delta E_{\mathrm{oi}}$ term, the dimerization energies of $\left[\mathrm{H}_{3} \mathrm{P}-\mathrm{M}-\mathrm{X}\right]_{2}$ would be largely reduced and in some cases, turn out positive (see $\Delta E_{\text {dim }}$ and $\Delta E_{\mathrm{oi}}$ in Table 2), meaning that the monomers would repel each other.

The $1 \sigma$ orbital consists of donor and acceptor $\operatorname{FMO}(\mathrm{s})$, where the main contributions to the donor orbitals come from 
the metal $n \mathrm{~d}$ orbitals and where the acceptor orbitals consist mainly of ligand $\sigma^{*} \mathrm{P}-\mathrm{H}$ orbitals and the metal $(n+1) \mathrm{s}$ and $(n$ $+1) p$ orbitals, indicating the influence of the ligand orbitals on metallophilic interactions of perpendicular dimers. In the equilibrium structures, there is a larger overlap with the acceptor orbitals for the $3 \mathrm{~d}$ metal $(\mathrm{Cu})$ than those for for $4 \mathrm{~d}$ $(\mathrm{Ag})$ and $5 \mathrm{~d}(\mathrm{Au})$, and $\Delta E_{\mathrm{D} / \mathrm{A}}$ is larger for $\mathrm{Ag}$ than those for $\mathrm{Au}$ and $\mathrm{Cu}$. Note that in the $\left[\mathrm{H}_{3} \mathrm{P}-\mathrm{M}-\mathrm{X}\right]$ dimers the $\Delta E_{\mathrm{D} / \mathrm{A}}$ gap between donor and acceptor is much higher $(4.20-6.13 \mathrm{eV})$ than those in the bare metals $(1.62-4.13 \mathrm{eV})$, which prevents a comparable mixing in of acceptor orbitals in these systems.

\section{CONCLUSION}

The MO analysis of $\mathrm{M}^{+} \cdots \mathrm{M}^{+}$is in a qualitative agreement with the hybridization picture introduced by Hoffmann ${ }^{4 a}$ (i.e., there is covalent attractive contribution to the metal-metal interaction). However, it is important to mention that if ligands are present, like in $\left[\mathrm{H}_{3} \mathrm{P}-\mathrm{M}-\mathrm{X}\right]_{2}$, Pauli repulsion is much more important than $\Delta E_{\mathrm{oi}}$ (compare Figure $3 \mathrm{a}, \mathrm{b}$ with Figure $3 \mathrm{~d}, \mathrm{e})$. In these cases, the electrostatic energy is the largest attractive interaction term. Still, attractive D-A interaction is present, but is overruled by two-orbital, fourelectron repulsion. Nevertheless, mixing of acceptor orbitals into the $1 \sigma$ leads to a stabilization of $\left[\mathrm{H}_{3} \mathrm{P}-\mathrm{M}-\mathrm{X}\right]_{2}$ systems, which would otherwise be nonbonding. Thus, an effective tuning of these interactions could be achieved if the acceptor orbitals are significantly stabilized. Studies which focus on the influence of the ligand acceptor orbital(s) are currently under progress.

\section{ASSOCIATED CONTENT}

\section{S Supporting Information}

The following files are available free of charge. SI_Inorg_Chem.pdf . The Supporting Information is available free of charge on the ACS Publications website at DOI: 10.1021/ acs.inorgchem.7b02994.

Details of the computational methods, benchmark study, equilibrium bond distances $(r)$ and dimerization energies of the optimized head-to-tail and perpendicular $\left[\mathrm{H}_{3} \mathrm{P}-\right.$ $\mathrm{M}-\mathrm{X}]$ dimers, gross orbital population analysis of the $\mathrm{M}^{+} \cdots \mathrm{M}^{+}$interaction, EDA of $\mathrm{M}^{+} \cdots \mathrm{M}^{+}$and $\left[\mathrm{H}_{3} \mathrm{P}-\mathrm{M}-\mathrm{X}\right]_{2}$ at different distances, total $\mathrm{SFO}$ gross populations analysis of donor and acceptor orbitals in $\mathrm{M}^{+} \cdots \mathrm{M}^{+}$and $\left[\mathrm{H}_{3} \mathrm{P}-\mathrm{M}-\mathrm{X}\right]_{2}$, major fragment molecular orbitals (FMOs) of the donor-acceptor interaction in $\left[\mathrm{H}_{3} \mathrm{P}-\right.$ $\mathrm{M}-\mathrm{X}]_{2}$, coordinates (XYZ) and constraints of all structures used in this study, including total bonding energies (TBE) and frequency analysis (PDF)

\section{AUTHOR INFORMATION}

\section{Corresponding Authors}

*E-mail: j.s.n.nitsch@vu.nl.

*E-mail: c.fonsecaguerra@vu.nl.

\section{ORCID $\odot$}

Jörn Nitsch: 0000-0002-4005-2257

Célia Fonseca Guerra: 0000-0002-2973-5321

\section{Notes}

The authors declare no competing financial interest.

\section{ACKNOWLEDGMENTS}

J.N. thanks the DFG for a Postdoctoral Research Fellowship (NI 1737/1-1). C.F.G. thanks The Netherlands Organization for Scientific Research (NWO/CW) for financial support.

\section{REFERENCES}

(1) (a) Pyykkö, P. Strong Closed-Shell Interactions in Inorganic Chemistry. Chem. Rev. 1997, 97, 597-636. (b) Pyykkö, P. Theoretical chemistry of gold. Angew. Chem., Int. Ed. 2004, 43, 4412-4456. (c) O'Grady, E.; Kaltsoyannis, N. Does metallophilicity increase or decrease down group 11? Computational investigations of [Cl-M$\left.\mathrm{PH}_{3}\right]_{2}(\mathrm{M}=\mathrm{Cu}, \mathrm{Ag}, \mathrm{Au},[111])$. Phys. Chem. Chem. Phys. 2004, 6, 680-687. (d) Schmidbaur, H.; Cronje, S.; Djordjevic, B.; Schuster, O. Understanding gold chemistry through relativity. Chem. Phys. 2005, 311, 151-161. (e) Pyykkö, P. Theoretical chemistry of gold. III. Chem. Soc. Rev. 2008, 37, 1967-1997. (f) Schmidbaur, H.; Schier, A. A briefing on aurophilicity. Chem. Soc. Rev. 2008, 37, 1931-1951. (g) Pyykkö, P.; Xiong, X.-G.; Li, J. Aurophilic attractions between a closed-shell molecule and a gold cluster. Faraday Discuss. 2011, 152, 169-178. (h) Muñiz, J.; Wang, C.; Pyykkö, P. Aurophilicity: The Effect of the Neutral Ligand L on $\left[\{\mathrm{ClAuL}\}_{2}\right]$ Systems. Chem. - Eur. J. 2011, 17, 368-377. (i) Sculfort, S.; Braunstein, P. Intramolecular $\mathrm{d}^{10}$ $\mathrm{d}^{10}$ interactions in heterometallic clusters of the transition metals. Chem. Soc. Rev. 2011, 40, 2741-2760. (j) Schmidbaur, H.; Schier, A. Aurophilic interactions as a subject of current research: an up-date. Chem. Soc. Rev. 2012, 41, 370-412. (k) Hupf, E.; Kather, R.; Vogt, M.; Lork, E.; Mebs, S.; Beckmann, J. Dispersion in Metallophilic Hg..M Interactions $(\mathrm{M}=\mathrm{Cu}, \mathrm{Ag}, \mathrm{Au})$ within Coinage Metal Complexes of Bis(6-diphenylphosphinoacenaphth-5-yl)mercury. Inorg. Chem. 2016, $55,11513-11521$.

(2) (a) Che, C.-M.; Lai, S.-W. Structural and spectroscopic evidence for weak metal-metal interactions and metal-substrate exciplex formations in $\mathrm{d}^{10}$ metal complexes. Coord. Chem. Rev. 2005, 249, 1296-1309. (b) Phillips, D. L.; Che, C.-M.; Leung, K. H.; Mao, Z.; Tse, M.-C A comparative study on metal-metal interaction in binuclear two- and three-coordinated $\mathrm{d}^{10}$-metal complexes. Spectroscopic investigation of $\mathrm{M}(\mathrm{I})-\mathrm{M}(\mathrm{I})$ interaction in the ${ }^{1}\left[\mathrm{~d} \sigma^{*} \mathrm{p} \sigma\right]$ excited state of $\left[\mathrm{M}_{2}(\mathrm{dcpm})_{2}\right]^{2+}(\mathrm{dcpm}=$ bis $($ dicyclohexylphosphino $)$ methane $)(\mathrm{M}$ $=\mathrm{Au}, \mathrm{Ag}, \mathrm{Cu})$ and $\left[\mathrm{M}_{2}(\mathrm{dmpm})_{3}\right]^{2+}(\mathrm{dmpm}=$ bis (dimethylphosphino)methane) $(\mathrm{M}=\mathrm{Au}, \mathrm{Ag}, \mathrm{Cu})$ complexes. Coord. Chem. Rev. 2005, 249, 1476-1490. (c) Chen, Z. N.; Zhao, N.; Fan, Y.; $\mathrm{Ni}$, J. Luminescent groups 10 and 11 heteropolynuclear complexes based on thiolate or alkynyl ligands. Coord. Chem. Rev. 2009, 253, 120. (d) Ito, H.; Muromoto, M.; Kurenuma, S.; Ishizaka, S.; Kitamura, N.; Sato, H.; Seki, T. Mechanical stimulation and solid seeding trigger single-crystal-to-single-crystal molecular domino transformations. Nat. Commun. 2013, 4, 2009. (e) Vickery, J. C.; Olmstead, M. M.; Fung, E. Y.; Balch, A. L. Solvent-stimulated luminescence from the supramolecular aggregation of a trinuclear gold(I) complex that displays extensive intermolecular $\mathrm{Au}-\mathrm{Au}$ interactions. Angew. Chem., Int. Ed. Engl. 1997, 36, 1179-1181. (f) Mansour, M. A.; Connick, W. B.; Lachicotte, R. J.; Gysling, H. J.; Eisenberg, R. Linear chain Au(I) dimer compounds as environmental sensors: A luminescent switch for the detection of volatile organic compounds. J. Am. Chem. Soc. 1998, 120, 1329-1330. (g) Seki, T.; Sakurada, K.; Muromoto, M.; Seki, S.; Ito, H. Detailed Investigation of the Structural, Thermal, and Electronic Properties of Gold Isocyanide Complexes with Mechano-Triggered Single-Crystal-to-Single-Crystal Phase Transitions. Chem. - Eur. J. 2016, 22, 1968-1978. (h) Nitsch, J.; Lacemon, F.; Lorbach, A.; Eichhorn, A.; Cisnetti, F.; Steffen, A. Cuprophilic interactions in highly luminescent dicopper(I)-NHC-picolyl complexes - fast phosphorescence or TADF? Chem. Commun. 2016, 52, 2932-2935. (i) El Sayed Moussa, M.; Evariste, S.; Wong, H. L.; Le Bras, L.; Roiland, C.; Le Polles, L.; Le Guennic, B.; Costuas, K.; Yam, V. W.-W.; Lescop, C. A solid state highly emissive $\mathrm{Cu}(\mathrm{I})$ metallacycle: promotion of cuprophilic interactions at the excited states. Chem. Commun. 2016, 52, 11370-11373. (j) Lima, J. C.; Rodríguez, L. Applications of gold(I) alkynyl systems: a growing field to explore. Chem. Soc. Rev. 
2011, 40, 5442-5456. (k) Che, C.-M.; Kwong, H.-L.; Yam, V. W.-W.; Cho, K.-C. Spectroscopic properties and redox chemistry of the phosphorescent excited state of $\left[\mathrm{Au}_{2}(\mathrm{dppm})_{2}\right]^{2+}[\mathrm{dppm}=$ bis(diphenylphosphino)methane]. J. Chem. Soc., Chem. Commun. 1989, 885-886. (1) Bestgen, S.; Gamer, M. T.; Lebedkin, S.; Kappes, M. M.; Roesky, P. W. Di- and trinuclear gold complexes of diphenylphosphinoethyl-functionalised imidazolium salts and their N-heterocyclic carbenes: synthesis and photophysical properties. Chem. - Eur. J. 2015, 21, 601-614. (m) Gagné, M. R.; Weber, D. In Homogeneous Gold Catalysis; Springer International Publishing: Cham, 2015; Vol. 357, pp 167-212 (and references herein).

(3) (a) Barreiro, E.; Casas, J. S.; Couce, M. D.; Laguna, A.; López-deLuzuriaga, J. M.; Monge, M.; Sánchez, A.; Sordo, J.; Varela, J. M.; López, E. M. V. A Dinuclear Gold(I)-Silver(I) Derivative of 2Cyclopentylidene-2-sulfanylacetic Acid and Related Complexes: Synthesis, Crystal Structures, Properties and Antitumor Activity. Eur. J. Inorg. Chem. 2011, 2011, 1322-1332. (b) Barreiro, E.; Casas, J. S.; Couce, M. D.; Sánchez, A.; Sánchez-González, A.; Sordo, J.; Varela, J. M.; Vázquez López, E. M. Dinuclear triphenylphosphinegold(I) sulfanylcarboxylates: Synthesis, structure and cytotoxic activity against cancer cell lines. J. Inorg. Biochem. 2010, 104, 551-559.

(4) (a) Schmidbaur, H.; Dziwok, K.; Grohmann, A.; Müller, G. Further Evidence for Attractive Interactions between Gold(I) Centers in Binuclear Complexes. Chem. Ber. 1989, 122, 893-895. (b) Harwell, D. E.; Mortimer, M. D.; Knobler, C. B.; Anet, F. A. L.; Hawthorne, M. F. Auracarboranes with and without $\mathrm{Au}-\mathrm{Au}$ interactions: An unusually strong aurophilic interaction. J. Am. Chem. Soc. 1996, 118, 2679-2685. (c) Deák, A.; Megyes, T.; Tárkányi, G.; Király, P.; Biczók, L.; Pálinkás, G.; Stang, P. J. Synthesis and solution- and solid-state characterization of gold(I) rings with short $\mathrm{Au} \cdots \mathrm{Au}$ interactions. Spontaneous resolution of a gold(I) complex. J. Am. Chem. Soc. 2006, 128, 12668-12670. (d) Arunan, E.; Desiraju, G. R.; Klein, R. A.; Sadlej, J.; Scheiner, S.; Alkorta, I.; Clary, D. C.; Crabtree, R. H.; Dannenberg, J. J.; Hobza, P.; Kjaergaard, H. G.; Legon, A. C.; Mennucci, B.; Nesbitt, D. J. Defining the hydrogen bond: An account. Pure Appl. Chem. 2011, 83, 1619-1636.

(5) (a) Mehrotra, P. K.; Hoffmann, R. Cu(I)-Cu(I) Interactions Bonding Relationships in $\mathrm{d}^{10}-\mathrm{d}^{10}$ Systems. Inorg. Chem. 1978, 17, 2187-2189. (b) Jiang, Y.; Alvarez, S.; Hoffmann, R. Binuclear and Polymeric Gold(I) Complexes. Inorg. Chem. 1985, 24, 749-757.

(6) Görling, A.; Rösch, N.; Ellis, D. E.; Schmidbaur, H. Electronic structure of main-group-element-centered octahedral gold clusters. Inorg. Chem. 1991, 30, 3986-3994.

(7) Evans, D. G.; Mingos, D. M. P. Molecular orbital analysis of the bonding in penta- and hepta-nuclear gold tertiary phosphine clusters. J. Organomet. Chem. 1985, 295, 389-400.

(8) (a) Pyykkö, P.; Zhao, Y. F. Ab initio Calculations on the $\left(\mathrm{ClAuPH}_{3}\right)_{2}$ Dimer with Relativistic Pseudopotential - Is the Aurophilic Attraction a Correlation Effect? Angew. Chem., Int. Ed. Engl. 1991, 30, 604-605. (b) Li, J.; Pyykkö, P. Relativistic Pseudopotential Analysis of the Weak $\mathrm{Au}(\mathrm{I}) \cdots \mathrm{Au}(\mathrm{I})$ Attraction. Chem. Phys. Lett. 1992, 197, 586-590. (c) Pyykkö, P.; Li, J.; Runeberg, N. Predicted Ligand Dependence of the $\mathrm{Au}(\mathrm{I}) \cdots \mathrm{Au}(\mathrm{I})$ Attraction in $\left(\mathrm{XAuPH}_{3}\right)_{2}$. Chem. Phys. Lett. 1994, 218, 133-138.

(9) Wang, S. G.; Schwarz, W. H. Quasi-relativistic density functional study of aurophilic interactions. J. Am. Chem. Soc. 2004, 126, 12661276.

(10) (a) Ziegler, T.; Rauk, A. On the calculation of bonding energies by the Hartree Fock Slater method. I. The transition state method. Theor. Chim. Acta 1977, 46, 1-10. (b) Bickelhaupt, F. M.; Baerends, E. J. Kohn-Sham density functional theory: predicting and understanding chemistry. Rev. Comput. Chem. 2000, 15, 1-86.

(11) Pinter, B.; Broeckaert, L.; Turek, J.; Růžička, A.; De Proft, F. Dimers of N-heterocyclic carbene copper, silver, and gold halides: probing metallophilic interactions through electron density based concepts. Chem. - Eur. J. 2014, 20, 734-744.

(12) Schwarz, W. H. E.; van Wezenbeek, E. M.; Baerends, E. J.; Snijders, J. G. The origin of relativistic effects of atomic orbitals. J. Phys. B: At., Mol. Opt. Phys. 1989, 22, 1515-1529. 